\title{
Cerebellar Metastasis as First Metastasis from Papillary Thyroid Carcinoma
}

\author{
KALLIOPI PAZAITOU-PANAYIOTOU, ATHINA KAPRARA, ALEXANDRA CHRISOULIDOU, \\ MARIA BOUDINA, ELENI GEORGIOU, FRIDERIKI PATAKIOUTA*, APOSTOLOS DRIMONITIS \\ AND IRAKLIS VAINAS \\ Department of Endocrinology-Endocrine Oncology, Theagenio Cancer Hospital, 2, A. Simeonidi street, 540 07, Thessaloniki, Greece \\ *Department of Pathology, Theagenio Cancer Hospital, 2, A. Simeonidi street, 540 07, Thessaloniki, Greece
}

\begin{abstract}
Brain metastasis is an uncommon complication of differentiated thyroid carcinoma. Even more, cerebellar metastases from papillary thyroid carcinoma (PTC) are exceptional. We report a 69-year-old male patient with infiltrative PTC who developed high levels of thyroglobulin (Tg) and deteriorated neurological symptoms four years after the initial diagnosis. Computerized tomography (CT) of the brain demonstrated a cerebellar mass and the patient underwent surgery. Pathology revealed metastasis from PTC. Immunochemistry was positive for Tg. The patient had no other sites of distant metastases. Although PTC has generally a good prognosis, metastases to the cerebellum can occur, even as the first metastatic site, despite the fact that appropriate therapy (surgery, radioactive iodine therapy, TSH suppression therapy, chemotherapy and external radiotherapy) had been given for the primary tumour.
\end{abstract}

Key words: Thyroid carcinoma, Cerebellar metastasis

(Endocrine Journal 52: 653-657, 2005)

PAPILLARY thyroid carcinoma (PTC) is the most common endocrine malignancy with indolent clinical course and good prognosis. It usually tends to metastasize locally to regional lymph nodes [1]. Distant metastases are rare, more commonly to lungs and bones, and suggest an aggressive disease [2]. Brain metastases are extremely rare, occurring in $0.15-1.3 \%$ of all cases of thyroid carcinoma [3, 4]. Brain metastases occur more frequently in the cerebral hemispheres and in most patients the brain is a site for second or subsequent metastases [5]. Cerebellar metastases from PTC are exceptional and only few cases are reported in the literature. Due to the rarity of the disease therapeutic modalities for these cases are not established $[1,6]$.

We report a patient with PTC who developed a mass in the right cerebellar hemisphere proved to be a

Received: May 13, 2005

Accepted: July 25, 2005

Correspondence to: Kalliopi PAZAITOU-PANAYIOTOU, Department of Endocrinology, Endocrine Oncology, Theagenio Cancer Hospital, 2, A. Simeonidi street, 540 07, Thessaloniki, Greece metastasis from PTC despite the fact that total thyroidectomy, ablation therapy with radioactive iodine, external radiation therapy and chemotherapy had been given for the primary tumour. It is important to underline that in our patient no other distant metastases could be established. To our knowledge, only in one other case cerebellum was the site of the first and solitary distant metastasis from PTC [7].

\section{Case Report}

A 69-year-old male patient was referred to our clinic in June 1998 for further evaluation and treatment after a fine needle aspiration cytology of a thyroid nodule suggestive of PTC. The patient had no personal or family history of thyroid disease and no previous history of head and neck irradiation.

When seen in clinic, he was in good general condition. He complained of hoarseness, dyspnea and productive cough of one year's duration. Clinical examination revealed a palpable mass in the central 
cervical region fixed with the surrounding tissues. Thyroid ultrasonography revealed a solitary nodule of $4 \mathrm{~cm}$ with irregular borders located at the isthmus. Thyroid scintiscan $\left({ }^{99 \mathrm{~m}} \mathrm{Tc}\right)$ showed a central cold nodule and computerized tomography (CT) of the neck demonstrated a mass $(4.5 \times 3.8 \mathrm{~cm})$ which infiltrated the trachea, without enlarged cervical lymph nodes. Thyroid function tests were normal. Thyroglobulin (Tg) autoantibodies were negative. Bronchoscopy revealed a mass below the level of vocal cords that seemed to push trachea from outside.

Due to these findings total thyroidectomy was performed in June 1998. Because of the infiltration of the trachea, trace of neoplastic tissue was left at the area. On gross examination, the thyroid gland was replaced by whitish and firm tumor sized $5 \times 4 \times 2 \mathrm{~cm}$ with papillary formations. The tumor was clearly invasive with extra thyroidal extension. Microscopically, the thyroid mass revealed a papillary carcinoma with typical architecture and characteristic nuclear features of PTC. Psammoma bodies were seen in the papillary stalk and in the fibrous stroma. Infiltration of the thyroid capsule and extra thyroidal extension into the soft tissues of the neck were confirmed (Fig. 1).

Postoperatively, thyroid ablation therapy with 100 $\mathrm{mCi}$ of radioactive iodine $\left({ }^{131} \mathrm{I}\right)$ was given. The whole body scan (WBS) seven days after iodine therapy indicated abnormal uptake at the central cervical region. Serum Tg levels were $29.6 \mathrm{ng} / \mathrm{ml}$ off thyroxine and TSH was $60.6 \mu \mathrm{U} / \mathrm{ml}(0.4-4 \mu \mathrm{U} / \mathrm{ml})$. Suppressive thyroxine therapy ( $175 \mu \mathrm{g}$ LT4 po daily) was prescribed in order to maintain TSH under $0.1 \mu \mathrm{U} / \mathrm{ml}$.
Due to the residual disease, infiltration of the trachea and extra thyroidal extension of the disease in the surrounding tissues, the patient received adjuvant chemotherapy with carboplatin and paclitaxel (6 cycles) and cervical and upper mediastinal external radiotherapy with ${ }^{60} \mathrm{Co}$ (total dose of $40 \mathrm{~Gy}$ divided into 20 doses). The patient was kept under close follow-up.

Nine months later, CT of the neck and lung did not indicate any residual or metastatic disease. Serum Tg levels were undetectable on thyroxine therapy. $\mathrm{Tg}$ autoantibodies were negative. In June 2000 the patient complained of headaches and numbness of feet and legs. Neurological examination showed normal symmetric reflexes, intact cranial nerves function and absence of meningeal signs. A WBS with $5 \mathrm{mCi}{ }^{131} \mathrm{I}$ showed decreased uptake at the cervical region, as compared to the post treatment WBS. No additional sites of abnormal ${ }^{131} \mathrm{I}$ uptake, including lung, bone or head, were seen. Serum Tg levels were $0.5 \mathrm{ng} / \mathrm{ml}$ and TSH $58.67 \mu \mathrm{U} / \mathrm{ml}$ on thyroxine withdrawal. CT of the brain was performed without any abnormal findings. Based on the normal neurological examination and negative imaging techniques, a recurrence or metastases of the diseases was excluded. Numbness of feet and legs were not attributed to a specific neurological disease. During the next two years the patient was in good general condition apart from numbness of feet and legs. Serum Tg levels on thyroxine therapy were undetectable.

In June $2002 \mathrm{Tg}$ levels rose up to $3.78 \mathrm{ng} / \mathrm{ml}$ on thyroxine while $\mathrm{Tg}$ concentration were $185 \mathrm{ng} / \mathrm{ml}$ on stopping thyroxine. At the same time, the patient start-

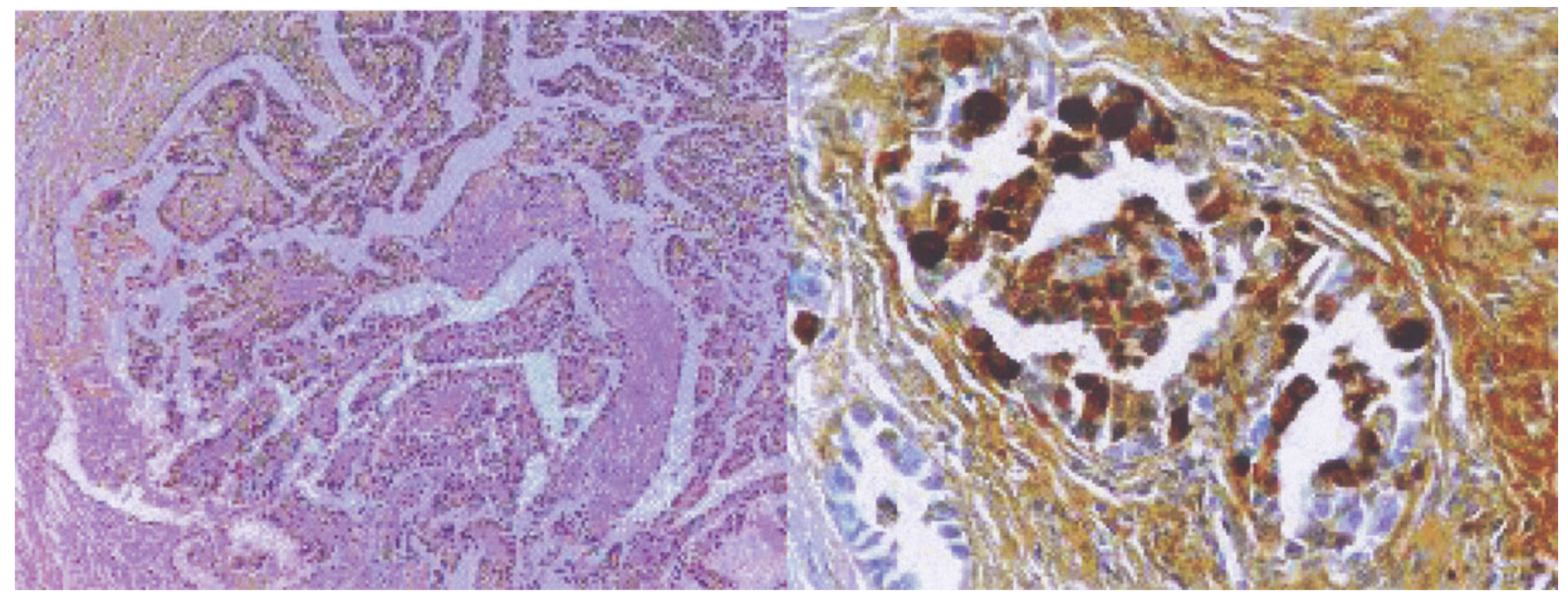

Fig. 1. Pathology of the thyroid. Typical growth pattern of papillary carcinoma. The papillae are complex and branching and contain a central fibro vascular core. Left: hematoxylin and eosin $\times 40$, right: thyreoglobulin $\times 200$. 
ed complaining of dizziness, headaches and unsteady gait. CT of the brain demonstrated a tumor to the right cerebellar hemisphere. At this point CT of the brain which was performed in June 2000, was extensively reevaluated it was found negative for tumor again. The findings of the new CT in association with $\mathrm{Tg}$ elevation were suggestive of metastatic disease and because of deteriorating symptoms, the patient underwent craniotomy. Total excision of the mass was impossible because of the size and site of the lesion. Eventually $1.8 \times 1.5 \mathrm{~cm}$ of neoplastic tissue was excised and the mass proved to be metastatic PTC (Fig. 2). Postopera- tively a WBS with $5 \mathrm{mCi}$ of iodine was performed after stimulation with exogenous recombinant human TSH (Thyrogen $0.9 \mathrm{mg}$ intramuscularly for two consecutive days). No intracranial accumulation was noted. Nevertheless a therapeutic administration of $200 \mathrm{mCi}$ of radioactive iodine $\left.{ }^{131} \mathrm{I}\right)$ therapy was scheduled. Meanwhile the patient received external cerebellar radiotherapy with ${ }^{60} \mathrm{Co}$ (total dose of $39 \mathrm{~Gy}$ divided in 13 doses) and for 4 months he was in good condition. After this period the neurological symptoms relapsed, the patient was obligate to remain at bed all day and the administration of radioactive iodine $\left({ }^{131} \mathrm{I}\right)$ therapy

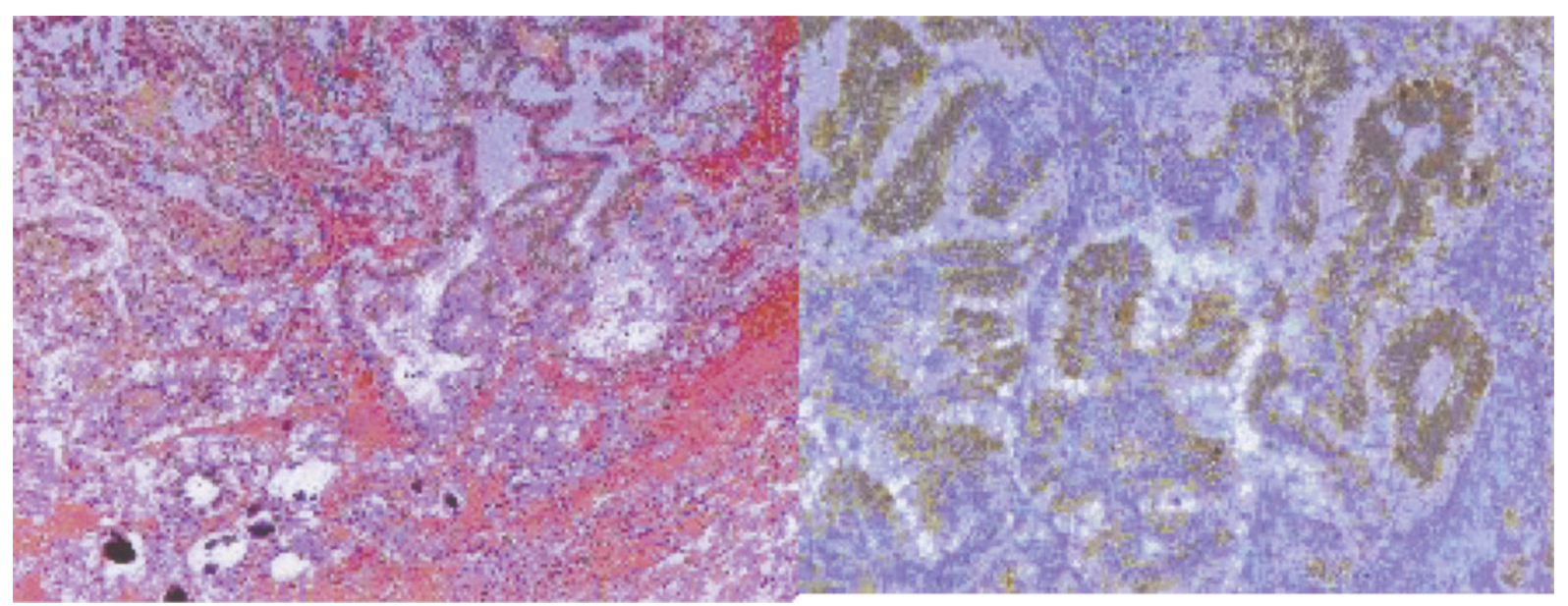

Fig. 2. Pathology of the cerebellum. Left: Cerebellar metastases of papillary thyroid carcinoma with psammoma bodies (hematoxylin and eosin $\times 40$ ), right: immunohistochemical stain for thyroglobulin of metastatic papillary thyroid carcinoma in the cerebellum (immunoperoxidase $\times 40$ ).
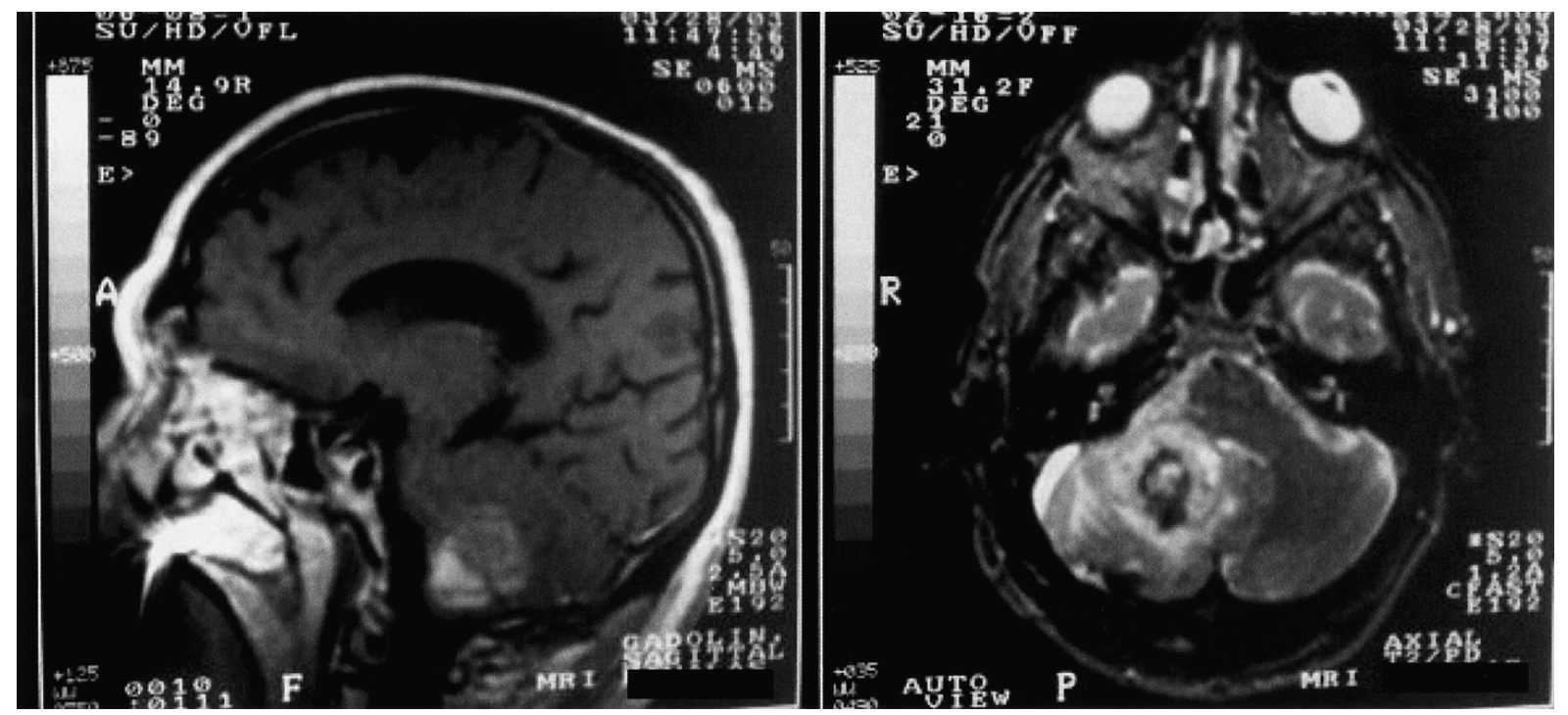

Fig. 3. Sagittal (left) and axial (right) views of computerized tomography of the brain which demonstrated a ring-enhancing lesion to the cerebellum accompanied by surrounding edema and compression of the fourth ventricle, two months after the brain'-s surgery. 
was cancelled. A magnetic resonance imaging (MRI) showed a ring-enhancing lesion to the cerebellum accompanied by surrounding edema and compression of the fourth ventricle (Fig. 3). The patient was admitted in the local hospital and started on $8 \mathrm{mg}$ dexamethasone im every 8 hours. Despite therapy the patient died one month later.

\section{Discussion}

Papillary thyroid carcinoma is the most common type of differentiated thyroid carcinoma (DTC). The prognosis is usually excellent and the reported survival rates for non metastatic lesions are $97.8 \%$ at 5 years and $94.9 \%$ at 10 years [8]. The presence of distant metastases diminishes the survival rates to $37 \%$ and $24 \%$ at 5 and 10 -year respectively. Lung is the most common site of distant metastases [5]. Brain metastases are uncommon. Few reports have appeared in the literature. Most frequently they were seen in the cerebral hemispheres and usually follow other metastases as lung or bone metastases. However, solitary cerebral metastases with no other evidence of metastatic disease have been reported. Aguiar et al. [9] reviewed the literature and found 75 cases of PTC metastatic to the central nervous system and only 12 cases of solitary brain metastases. In particular, cerebellar metastases from PTC are extremely rare $[1,6]$ and only four cases are reported in the literature, two in the cerebellar hemisphere $[10,11]$ and one in the cerebellopontine angle [7]. Carcangiu et al. [12] noted one case of a metastasis in the cerebellopontine angle too, in a retrospective review of 241 cases of PTC, although there were not any details concerning metastatic status of the case. In our case the cerebellar hemisphere was involved and was the only site of distant metastases. To our knowledge, this is the second case of solitary cerebellar metastasis, which is reported in the literature [7].

In many centers during the follow up of patients with DTC a ${ }^{131} \mathrm{I}$ WBS and serum Tg in the hypothyroid state are performed in order to estimate the progression of the disease and recognize distant metastases. ${ }^{131}$ I scan performed in our patient two years prior to brain metastases revealed no intracranial accumulation. It is reported that metastatic lesions from DTC may be less differentiated than the primary tumor, thus not accumulating radioactive iodine [3]. In such cases, a WBS may not help in establishing the diagnosis. A high serum $\mathrm{Tg}$ level may be helpful to identify metastases from DTC. If there is a suspicion of brain metastases, a head CT or MRI should be done and may be conclusive. However, the confirmation of the diagnosis is provided only from histologic examination [7].

The optimal management of PTC consists of total or near total thyroidectomy and ablation of the thyroid remnant with radioactive iodine. Patients over the age of 45 with residual disease and extra thyroidal extension are more likely to die from their disease than patients without extra thyroidal extension [13]. Ablation therapy with ${ }^{131}$ I may not be sufficient to eliminate residual disease. In these patients the use of external radiation may play a role as adjuvant therapy to surgical excision and ${ }^{131} \mathrm{I}$. External radiation therapy has been used for the treatment of residual disease or local recurrence and distant metastases in DTC [14]. Philips et al. [15] reported a local relapse rate of $3 \%$ for those who received external radiation therapy and $21 \%$ for those who did not suggesting an improved local control in a selected group of high risk patients with locally advanced PTC and extra thyroidal extension. The experience with chemotherapy in DTC is small, and probably its value is limited [16]. Combined therapy results in a higher response rate than monotherapy (26\% vs $17 \%)$ [17]. In our case, the patient was operated and received $100 \mathrm{mCi}{ }^{131} \mathrm{I}$. Patient's characteristics at the time of diagnosis (age 69 and a large infiltrative tumor sized $4.5 \times 3.8 \mathrm{~cm}$, residual disease, and extra thyroidal local extension) represented unfavorable prognostic factors. For this reason he received chemotherapy and external radiotherapy. None of the initial treatment modalities for the primary thyroid tumor affected the evolution of the disease and the appearance of distant metastases.

There is no clearly defined protocol concerning the management of intracranial metastases from PTC, possibly due to its rarity. The presence of a brain metastasis is a negative prognostic factor and the reported survival is less than a year. Therapy is quite individualized. Treatment of cerebral metastases may induce life-threatening complications such as cerebral edema [18], or sudden hemorrhage within the cerebral metastases after ${ }^{131}$ I therapy [19]. Surgery, external radiotherapy and radioactive iodine therapy have been used with varying results. The best therapeutic option seems to be resection [20], followed by radioactive iodine therapy [7]. Patients with DTC who underwent 
resection of one or more foci of brain metastases had longer survival than those who did not [20]. External radiation can be used as an adjunct to surgery. Extensive studies using this approach in brain metastatic disease are not available and the benefit of this approach is not well known. In our case, total surgical resection of the metastatic lesion was not possible. Therefore, external radiation therapy was given, which resulted in improvement of neurological symptoms for some months.

In conclusion, we report the rare case of solitary cerebellar metastasis in a patient with PTC, in whom other distant metastases were not established. The primary tumor was locally advanced at the time of diagnosis. After thyroidectomy and despite adjuvant treatment, the patient developed neurological symptoms and was treated with surgery and radiotherapy. Shrinkage of the metastasis led initially to clinical improvement, but relapse was soon observed, the neurological symptoms got worse and the patient died five years after the initial diagnosis.

\section{References}

1. Hoie J, Stenwing AE, Kullmann G, Lindegaard M (1988) Distant metastases in papillary thyroid cancer: a review of 91 patients. Cancer 61: 1-6.

2. Robbins J, Merino MJ, Boice JD Jr, Ron E, Ain KB, Alexander HR, Norton JA, Reynolds J (1991) Thyroid cancer: a lethal endocrine neoplasm. Ann Intern Med 115: 133-147.

3. Parker LN, Wu SY, Kim DD, Kollin J, Prasasvinichai S (1986) Recurrence of papillary thyroid carcinoma presenting as a focal neurologic deficit. Arch Intern Med 146: 1985-1987.

4. McCohaney WM, Hay ID, Woolner LB, van Heerden JA, Taylor WF (1986) Papillary thyroid cancer treated at the Mayo clinic, 1946 through 1970: Initial manifestation, pathologic findings, therapy and outcome. Mayo Clin Proc 61: 978-996.

5. Dinneen SF, Valmaki MJ, Bergstralh EJ, Goellner JR, Gorman CA, Hay ID (1995) Distant metastasis in papillary thyroid carcinoma: 100 cases observed at one institution during 5 decades. J Clin Endocrinol Metab 80: 2041-2045.

6. Ota T, Bando Y, Hirai M, Tanaka N, Takabatake Y, Kasahara Y, Fujisawa M (2001) Papillary carcinoma of the thyroid with distant metastases to the cerebrum: a case report. Jpn J Clin Oncol 31: 112-115.

7. Cha ST, Jarrahy R, Mathiesen RA, Suh R, Shahinian HK (2000) Cerebellopontine angle metastasis from papillary carcinoma of the thyroid:case report and literature review. Surg Neurol 54: 320-326.

8. Mazzaferri EL, Young RL, Oertel JE, Kemmerer WT, Page PC (1977) Papillary thyroid carcinoma: the impact of therapy in 576 patients. Medicine 56: 171-196.

9. Aguiar PH, Agner C, Tavares FR, Yamaguchi N (2001) Unusual brain metastases from papillary thyroid carcinoma: Case report. Neurosurgery 49: 1008-1013.

10. Pacak K, Sweeney DC, Wartofsky L, Mark AS, Punja
U, Azzam CJ, Burman KD (1998) Solitary cerebellar metastasis from papillary thyroid carcinoma: a case report. Thyroid 8: 327-335.

11. Jyothirmayi R, Edison J, Nayar PP, Nair MK, Rajan B (1995) Case report: brain metastases from papillary carcinoma thyroid. Br J Radiol 68: 767-769.

12. Carcangiu ML, Zampi G, Pupi A, Castagnoli A, Rosai J (1985) Papillary carcinoma of the thyroid: a clinicopathologic study of 241 cases treated at the University of Florence, Italy. Cancer 55: 805-828.

13. Andersen PE, Kinsella J, Loree TR, Shaha AR, Shah JP (1995) Differentiated carcinoma of the thyroid with extrathyroid extension. Am J Surg 170: 467-470.

14. Simpson WJ (1990) Radioiodine and radiotherapy in the management of thyroid cancers. Otolaryngol Clin North Am 23: 509-521.

15. Phlips P, Hanzen C, Andry G, Van Houtte P, Fruuling J (1993) Postoperative irradiation for thyroid cancer. Eur J Surg Oncol 19: 399-404.

16. Ekman ET, Lundell G, Tennvall J, Wallin G (1990) Chemotherapy and multimodality treatment in thyroid carcinoma. Otolaryngol Clin North Am 23: 523-527.

17. Shimaoka K, Schoenfeld DA, DeWys WD, Creech RH, DeConti R (1985) A randomized trial of doxorubicin vs. doxorubicin plus cisplatin in patients with advanced thyroid carcinoma. Cancer 56: 2155-2160.

18. Datz FL (1986) Cerebral edema following iodine-131 therapy for thyroid carcinoma metastatic to brain. $J$ Nucl Med 27: 637-640.

19. Holmquest DL, Lake P (1976) Sudden hemorrhage in metastatic thyroid carcinoma of the brain during treatment with iodine-131. J Nucl Med 17: 307-309.

20. Chiu AC, Delpassand ES, Sherman SI (1997) Prognosis and treatment of brain metastases in thyroid carcinoma. J Clin Endocrinol Metab 82: 3637-3642. 